\title{
ДИСКУССИИ
}

DOI: https://doi.org/10.15688/jvolsu2.2018.2.16

UDC 81'1:165.12

Submitted: 31.01 .2018

LBC 81.003

Accepted: 05.03.2018

\section{METALANGUAGE CONSCIOUSNESS: STRUCTURE AND CONTENT OF THE CONCEPT}

\author{
Evgeniy B. Ivannikov
}

Herzen State Pedagogical University, Saint Petersburg, Russia

\begin{abstract}
A narrow and wide understanding of the metalanguage consciousness is presented in the article as a set of metalinguistic consciousness levels, which are subconscious, verbalized and creative ones, and every level demonstrates its specificity. The author proves that subconscious and verbalized levels of metalanguage consciousness correspond to deep and surface levels of linguistic consciousness. The paper is also focused on features of metalinguistic consciousness, which embraces dual characteristics, including ontologism and gnoseologism, intuitivity and rationality, pragmatism and conceptual-terminological vagueness, prescientific and scientific character, objectivity and subjectivity; it describes main antinomies of metalinguistic consciousness: community or individuality; part or whole; creativity or automatism; common or scientific character; unconsciousness or awareness. The ratio of metalanguage consciousness levels and various areas of linguistics is characterized in terms of hierarchy of metalinguistic consciousness, provided that ordinary reflection and ordinary metalinguistic consciousness of an average native speaker are part of ordinary linguistics; scientific reflection and professional metalinguistic consciousness of a linguist are part of scientific linguistics. Accordingly, ordinary linguistics forms a linguistic (naive) picture of the world, whereas scientific linguistics a scientific picture of the world. It is concluded that metalinguistic consciousness is a part of linguistic consciousness, but its functions overcome the intralanguage boarders.

Key words: metalinguistic consciousness, linguistic consciousness, ordinary metalinguistic consciousness, professional metalanguage consciousness, naive linguistics, scientific linguistics.

Citation. Ivannikov E.B. Metalanguage Consciousness: Structure and Content of the Concept. Vestnik Volgogradskogo gosudarstvennogo universiteta. Seriya 2, Yazykoznanie [Science Journal of Volgograd State University. Linguistics], 2018, vol. 17, no. 2, pp. 143-150. (in Russian). DOI: https://doi.org/10.15688/jvolsu2.2018.2.16
\end{abstract}

УДК $81 ’ 1: 165.12$

Дата поступления статьи: 31.01.2018

ББК 81.003

Дата принятия статьи: 05.03.2018

\section{МЕТАЯЗЫКОВОЕ СОЗНАНИЕ: СТРУКТУРА И СОДЕРЖАНИЕ ПОНЯТИЯ}

\section{Евгений Борисович Иванников}

Российский государственный педагогический университет им. А.И. Герцена, г. Санкт-Петербург, Россия

\footnotetext{
Аннотация. В статье на основе анализа современной научной литературы представлена структура метаязыкового сознания: охарактеризованы его уровни (подсознательный, вербализированный, творческий). Показано, что подсознательный и вербализированный уровни метаязыкового сознания соответствуют глубинному и поверхностному уровням языкового сознания. Определено понятие обыденного метаязыкового сознания, имеющего
} 
такие двойственные характеристики, как онтологичность и гносеологичность; интуитивность и рационалистичность; прагматичность и понятийно-терминологическая нечеткость; донаучность и научность; объектность и субъектность. Установлены и представлены как антиномии основные свойства метаязыкового сознания: общественность / индивидуальность; часть / целое; креативность / автоматизированность; обыденность / научность; неосознанность / осознанность. Показано соотношение уровней метаязыкового сознания и различных областей лингвистики, проявляющееся в том, что подсознательный уровень метаязыкового сознания, обыденная рефлексия и обыденное метаязыковое сознание рядового носителя языка входят в область обыденной лингвистики; научная рефлексия и профессиональное метаязыковое сознание лингвиста входят в область научной лингвистики. При этом обыденная лингвистика образует языковую (наивную) картину мира; научная лингвистика - научную картину мира. Вывод о том, что метаязыковое сознание, будучи частью языкового сознания, в то же время функционирует за его пределами, позволяет разграничить термины «метаязыковое сознание» и «языковое сознание».

Ключевые слова: метаязыковое сознание, языковое сознание, обыденное метаязыковое сознание, профессиональное метаязыковое сознание, обыденная лингвистика, научная лингвистика.

Цитирование. Иванников Е. Б. Метаязыковое сознание: структура и содержание понятия // Вестник Волгоградского государственного университета. Серия 2, Языкознание. - 2018. - Т. 17, № 2. - С. 143-150. DOI: https://doi.org/10.15688/jvolsu2.2018.2.16

\section{Введение}

На современном этапе формирования гуманитарной науки возникает необходимость терминологического упорядочения в области исследования языка и мышления. Так, по-разному понимается термин «метаязыковое сознание». Зачастую он используется как синоним термина «языковое сознание». Этому способствует, по мнению лингвистов, ряд причин: во-первых, термины хронологически относятся к разными этапам развития лингвистики; вовторых, создание терминов проходило в русле разнообразных научных направлений и школ; в-третьих, размытость и неоднозначность границ терминов объясняется многоаспектностью, глубиной и низким уровнем определенности самого понятия «сознание» [Кравченко, Кравченко, 2015, с. 106]. Однако достижения в изучении метаязыковой деятельности человека дают основания для разграничения терминов «языковое сознание» и «метаязыковое сознание» как обозначающих разные феномены.

Систематизация современной научной литературы позволяет представить объем понятия «метаязыковое сознание» и аргументировать тем самым разграничение этих терминов.

\section{Метаязыковое сознание: узкое и широкое понимание}

В науке сложились два подхода к пониманию метаязыкового сознания, условно обозначаемые как узкий и широкий.
При узком понимании метаязыковое сознание - часть языкового сознания, функционирующая только на поверхностном уровне языкового сознания. В соответствии с этим метаязыковое сознание определяется как «область рационально-логического, рефлексирующего языкового сознания, направленного на отражение языка-объекта как элемента действительного мира» [Ростова, 2006, с. 24].

Метаязыковое сознание, будучи поверхностным уровнем языкового сознания, выражается «в рефлексии говорящего по поводу языковой организации, в суждениях индивида о языке, о собственных речевых тактиках». Поверхностный уровень организует «мышление о языке» [Ростова, 2008, с. 50]. Узкого понимания метаязыкового сознания придерживается и Н.Д. Голев, указывающий на то, что существуют две формы языкового сознания: собственно языковое сознание и метаязыковое сознание, при котором «носитель языка встает “над” языком, выступая в роли субъекта, познающего язык во всех его ипостасях и самого себя как носителя языка» [Голев, 2009а, с. 7].

При широком понимании метаязыковое сознание определяется как «область знания человека о своем языке» [Шафтельская, 2012, с. 125]. Оно лишь частично пересекается с языковым сознанием, поскольку включает в свою структуру не только поверхностный уровень языкового сознания, но и область бессознательного, а также собственно метаязыковую деятельность, выраженную в различных формах языкового творчества. Именно 
поэтому сторонники широкого понимания полагают, что метаязыковое сознание «нельзя редуцировать до компонента языкового сознания» [Кравченко, Кравченко, 2015, с. 107].

\section{Структура метаязыкового сознания}

Содержание понятия «метаязыковое сознание» получает отражение в его структуре. Согласно концепции М.Р. Шумариной, метаязыковое сознание имеет структуру, состоящую из трех уровней:

- подсознательный (бессознательный). На этом уровне речевой самоконтроль реализуется автоматизированно и бессознательно. Метаязыковое сознание представлено в имплицитном состоянии;

- вербализированный. На этом уровне речевой самоконтроль реализуется либо в исправлении допущенных ошибок и неточностей, либо в предвидении и предупреждении возможного коммуникативного сбоя. В метаязыковой рефлексии звучит своеобразное оправдание в употреблении того или иного выражения и дается оценка используемым речевым средствам. Метаязыковое сознание представлено в эксплицитном состоянии;

- творческий. На этом уровне субъект рефлексии не просто осознает объект, но сознательно выделяет его и подвергает творческому переосмыслению. В результате происходят определенного рода приращения, метаязыковая рефлексия обогащает содержание объекта и расширяет возможности его использования и интерпретации [Шумарина, 2011, c. 46-49].

Первый уровень метаязыкового сознания выражен в так называемой «нерефлектирующей рефлексии», под которой понимается «свободное ассоциирование, первая реакция на интерпретируемый знак, бессознательная, мгновенная, автоматическая, обнаруживающаяся в оценках воспринимающего знак субъекта» [Дударева, 2010, с. 289]. Первый уровень метаязыкового сознания в концепции М.Р. Шумариной соотносится с глубинным уровнем языкового сознания в концепции А.Н. Ростовой. Общими функциональными признаками данных уровней являются регуляция речемыслительной деятельности и контроль автоматизированных действий говоряще- го при порождении речи. Причина такой размытости границ метаязыкового сознания связана с тем, что метаязыковое сознание «включает не только сферу явного, вербализованного, но и сферу скрытого осознания» [Ростова, 2000 , c. 45].

Второй уровень метаязыкового сознания, согласно А.Ф. Колясевой, включает два подуровня:

- теоретически несистематизированное сознание;

- теоретически систематизированное сознание [Колясева, 2014, с. 157].

Первыци подуровень реализуется в форме многочисленных «эмпирических знаний и представлений о языке основной массы говорящих» и функционирует в сфере обыденного сознания [Блинова, 2012, с. 168]. Второй подуровень реализуется «в форме системы научных понятий, суждений, теоретических доказательств» [Блинова, 2012, с. 168] и функционирует в сфере профессиональной лингвистики. Соответственно, первый подуровень определяется как обыденное метаязыковое сознание рядовых носителей языка, а второй как профессиональное метаязыковое сознание лингвистов [Левенталь, 2014, с. 78].

Второй уровень метаязыкового сознания в концепции М.Р. Шумариной тождествен «поверхностному уровню языкового сознания», выделенному А.Н. Ростовой. Соответственно, при узком понимании метаязыковое сознание рассматривается как совокупность двух разновидностей сознания: обыденного метаязыкового сознания рядовых носителей языка и профессионального метаязыкового сознания лингвистов. При этом обыденное метаязыковое сознание первично по отношению к профессиональному (лингвистическому) метаязыковому сознанию, так как любая научная работа начинается с обыденной метаязыковой деятельности [Трофимова, 2009, с. 46].

Отдельного рассмотрения заслуживает обыденное метаязыковое сознание (далее $\mathrm{OMC}$ ), которое «является фундаментальной категорией, существенно влияющей на повседневную речевую практику, на преподавание языка в школе и вузе, на решение вопросов языкового строительства, на состояние ментальности в обществе и, наконец, опосредованно или прямо на саму науку о языке» [Голев, 2008, с. 5]. 
Обыденное метаязыковое сознание играет важную роль в формировании языковой компетенции говорящих [Ундармаа, 2014, с. 48]. ОМС понимается как «совокупность знаний, представлений, суждений о языке, элементах его структуры, их формальной и смысловой соотносительности, функционировании, развитии и т. д.» [Ростова, 2000, с. 45].

Обыденное метаязыковое сознание обладает рядом признаков, которые имеют двойственный характер.

Онтологичность - гносеологичность

Онтологическая сущность ОМС выражена в том, что оно, по мнению М.Р. Шумариной, является частью наивной картины мира [Шумарина, 2009, с. 220]. ОМС взаимосвязано с гносеологией: «с уровнем развития цивилизации, науки и самопознания человека, со стилем мышления, техническим прогрессом, актуальными в данном культурном контексте гносеологическими, стратегическими и тактическими проблемами и методами познания, особенно способностей и возможностей человека и т. п. Это проявляется в рефлексии представлений, стереотипов, предубеждений, противоречий и т. п.» [Базылев, 2012, с. 235].

Интуитивность - рационалистичность

Такая двойственность выражена в том, что обыденное метаязыковое сознание «на практике ориентируется на интуицию, а рефлектирует по поводу языка в рационалистических модальностях и понятиях» [Голев, 2009б, c. 281].

Прагматичность - понятийно-терминологическая нечеткость

Обыденное метаязыковое сознание характеризуется высокой степенью «детерминированности метаязыковых представлений практическим опытом дискурсивной деятельности». При этом «метаязыковые операторы, используемые рядовыми носителями языка, довольно регулярно не совпадают в своем значении с соответствующими лингвистическими терминами» [Шумарина, 2010, с. 301].

Донаучность - научность

ОМС взаимосвязано с донаучным и научным контекстом, то есть «с практическим, обыденным, донаучным языком и научным знанием и его языком, пусть даже и весьма маргинально» [Базылев, 2012, с. 234].
Объектность - субъектность

Обыденное метаязыковое сознание предполагает одновременно фокусирование внимания на деятельности слушающего и адресата речевого произведения, занимающего двойственную объектно-субъектную позицию [Ким, 2010, с. 94].

ОМС как часть естественного языка осмысленно «использует все имеющиеся в языке внутренние ресурсы, когнитивные и коммуникативные, лексические и грамматические, структурные и системные: метафору, метонимию, словообразование, синонимию, антонимию, аналогию, заимствования» [Базылев, 2012, с. 234]. При этом ОМС уделяет повышенное внимание функциональной стороне языка. Это «проявляется не только в комментировании социальных функций языка, в приписывании слову определенной (иногда магической) силы, но и в постоянном "контроле" за свойствами, которые обеспечивают пользователю “удобство”» при употреблении языка [Шумарина, 2009, с. 220]. Таким образом, обыденное метаязыковое сознание поддерживает своеобразный «комфорт» использования языка.

ОМС объединяет различные системы: язык и сознание, обыденное сознание и лингвистическое сознание, ментально-языковую и социальную жизнь человека, сопряженные с языковой деятельностью [Голев, 2008, с. 5].

Третий уровень - творческая рефлексия - реализуется в сложных трансформациях, результаты которых проявляются на втором уровне метаязыкового сознания: лингвистическое мифотворчество и языковая игра преобразуются в теоретически несистематизированное сознание (обыденные метаязыковые представления), а научно-исследовательское творчество лингвиста выступает источником пополнения теоретически систематизированного сознания (научно-лингвистическое знание). Кроме того, на третьем уровне метаязыкового сознания функционирует эстетическая рефлексия, выраженная в различных текстах: художественных, художественно-публицистических, фольклорных.

Таким образом, третий уровень метаязыкового сознания представлен следующими формами творческой рефлексии: научной, обыденной и эстетической. 
Научная рефлексия связана с научноисследовательским творчеством лингвиста и формирует научно-лингвистическое знание, которое «усваивается коллективным и индивидуальным метаязыковым сознанием и воспроизводится уже в процессе стандартизованной рефлексии, которая действует на втором уровне метаязыкового сознания» [Шумарина, 2011, c. 51].

Обыденная рефлексия языка обусловлена лингвистическим мифотворчеством и языковой игрой и формирует обыденное знание, выраженное в нестандартных, личностно окрашенных комментированиях фактов языка / речи [Шумарина, 2011, с. 49].

Эстетическая рефлексия выражается в художественном творчестве и «является "художественным освоением" различных положений о языке и речи в эстетически организованных текстах» [Шумарина, 2011, с. 50]. Эстетическая рефлексия формирует поэтическое метаязыковое сознание, которое, в отличие от обыденного метаязыкового сознания, всегда осознанно и вербализованно, а также сближается одновременно с обыденным и с научным сознанием [Кузьмина, 2009, с. 208-209].

Научная рефлексия и профессиональное метаязыковое сознание лингвиста входят в область так называемой научной лингвисти$\kappa u$, образующей научную картину мира [Ефремов, 2009, с. 34-35].

Подсознательный уровень метаязыкового сознания, обыденная рефлексия и обыденное метаязыковое сознание рядового носителя языка входят в область так называемой обыденной лингвистики, которая понимается как «метаязыковая деятельность индивида в области восприятия лексических, фонетических, грамматических, стилистических и прочих явлений в языке» [Трофимова, 2009, c. 47]. Обыденная лингвистика образует языковую (наивную) картину мира.

\section{Свойства метаязыкового сознания}

Широкое понимание метаязыкового сознания позволяет трактовать его как «сложный и противоречивый феномен, формируемый под воздействием разных детерминант» [Голев, 2012, c. 326] и характеризующийся рядом свойств, которые можно представить как антиномии.
Общественность / индивидуальность

Метаязыковое сознание как форма общественного сознания «является частью национального менталитета наряду с другими формами обыденного сознания» [Шапилова, 2010, с. 111]. При этом метаязыковое сознание, будучи общественным явлением, имеет индивидуальную форму объективации.

Часть / целое

Метаязыковое сознание одновременно является и частью языкового сознания, и отдельным целым, выходящим за рамки языкового сознания. Данный диалектический характер структуры метаязыкового сознания обусловлен тем, что «метаязыковое сознание имеет широкий диапазон форм - от “молчаливой рефлексии" рядовых носителей языка до серьезной теоретической рефлексии профессиональных лингвистов» [Левенталь, 2014, с. 78]. ность

Креативность / автоматизирован-

Основными источниками пополнения вербализированного уровня метаязыкового сознания являются различные формы творческой рефлексии, отражающие креативную сущность метаязыкового сознания. При этом некоторая метаязыковая деятельность вербализированного уровня метаязыкового сознания может доводиться до автоматизма и переходить на подсознательный уровень метаязыкового сознания.

\section{Обыденность / научность}

Обыденность является одним из важнейших признаков метаязыкового сознания [Левенталь, 2014, с. 78]. Она отражает область обыденной лингвистики, включающей подсознательное обыденное метаязыковое сознание и обыденную рефлексию рядового носителя языка. Обыденная лингвистика противопоставлена научной лингвистике, которая состоит из профессионального метаязыкового сознания и научной рефлексии лингвиста. При этом научная лингвистика развивается на основе обыденной лингвистики. Соответственно, обыденность, с одной стороны, противопоставлена научности, а с другой - является ее основой.

Неосознанность / осознанность

Некоторые уровни метаязыкового сознания реализуются как в подсознательной, так и в сознательной областях: на первом уровне метаязыкового сознания это рефлексия в им- 
плицитном состоянии («нерефлектирующая рефлексия»); на втором и третьем уровнях это рефлексия в эксплицитном состоянии, то есть в вербализированной форме.

\section{Выводы}

Метаязыковое сознание имеет структуру, состоящую из трех уровней: подсознательного, вербализированного, творческого, каждый из которых характеризуется рядом особенностей и свойств. Уровни метаязыкового сознания соотносятся с различными областями лингвистики: подсознательный уровень метаязыкового сознания, обыденная рефлексия и обыденное метаязыковое сознание рядового носителя языка входят в область обыденной лингвистики; научная рефлексия и профессиональное метаязыковое сознание лингвиста входят в область научной лингвистики.

Термины «метаязыковое сознание» и «языковое сознание» необходимо разграничивать, так как метаязыковое сознание одновременно является частью языкового сознания и в то же время выходит за его пределы. Подсознательный и вербализированный уровни метаязыкового сознания соотносятся с глубинным и поверхностным уровнями языкового сознания. Творческий уровень метаязыкового сознания не соответствует ни одному уровню языкового сознания, реализуя различные формы творческой рефлексии.

\section{СПИСОК ЛИТЕРАТУРЫ}

Базылев В. Н., 2012. Релевантность и нерелевантность метаязыкового знания как категории диахронического описания повседневного опыта // Обыденное метаязыковое сознание: онтологические и гносеологические аспекты / отв. ред. Н. Д. Голев. Кемерово : Кемеровский гос. ун-т. Ч. IV. С. 231-241.

Блинова О. И., 2012. Лексикографический способ исследования метаязыкового сознания // Обыденное метаязыковое сознание: онтологические и гносеологические аспекты / отв. ред. Н. Д. Голев. Кемерово : Кемеровский гос. ун-т. Ч.IV. C. $168-177$.

Голев Н. Д., 2008. Особенности современного обыденного метаязыкового сознания в зеркале обсуждения вопросов языкового строитель- ства // Вестник Томского государственного университета. Филология. № 3 (4). С. 5-17.

Голев, Н. Д., 2009а. Обыденное метаязыковое сознание как онтолого-гносеологический феномен (к поискам «лингвогносеологем») // Обыденное метаязыковое сознание: онтологические и гносеологические аспекты / отв. ред. Н. Д. Голев. Кемерово ; Барнаул : Изд-во Алтайского гос. ун-та. Ч. І. С. 7-40.

Голев Н. Д., 2009б. Современное российское обыденное метаязыковое сознание между наукой и школьным курсом русского языка («правильность» как базовый постулат наивной лингвистики) // Обыденное метаязыковое сознание: онтологические и гносеологические аспекты / отв. ред. Н. Д. Голев. Томск : Томский гос. пед. ун-т. Ч. II. С. 261-282.

Голев Н. Д., 2012. Вариативность метаязыкового сознания студентов-филологов и научный плюрализм (антиномический анализ проблемы) // Обыденное метаязыковое сознание: онтологические и гносеологические аспекты / отв. ред. Н. Д. Голев. Кемерово : Кемеровский гос. ун-т. Ч. IV. С. 306-330.

Дударева Я. А., 2010. Ассоциативно-интерпретационная деятельность рядовых носителей русского языка при определении тождества, сходства и различия товарных знаков // Обыденное метаязыковое сознание: онтологические и гносеологические аспекты / отв. ред. Н. Д. Голев. Кемерово : Кемеровский гос. ун-т. Ч. III. С. 286-292.

Ефремов В. А., 2009. «Мужчина» и «женщина» в русской языковой картине мира. СПб. : Изд-во РГПУ им. А.И. Герцена. 184 с.

Ким Л. Г., 2010. Текст как объект метаязыковой деятельности субъекта-интерпретатора // Обыденное метаязыковое сознание: онтологические и гносеологические аспекты / отв. ред. Н. Д. Голев. Кемерово : Кемеровский гос. ун-т. Ч. III. С. 94-109.

Колясева А. Ф., 2014. Терминология в зеркале языкового сознания // Филология и человек. № 2. C. $151-161$.

Кравченко М. А., Кравченко О. В., 2015. О соотношении понятий «языковое сознание» и «метаязыковое сознание» // Филологические науки. Вопросы теории и практики. № 9, ч. 1. C. $105-108$.

Кузьмина Н. А., 2009. Автокомментирование как форма проявления метаязыкового сознания (на материале русской поэзии новейшего времени) // Обыденное метаязыковое сознание: онтологические и гносеологические аспекты. / отв. ред. Н. Д. Голев. Томск : Томский гос. пед. ун-т. Ч. II. С. 192-209. 
Левенталь И. В., 2014. Стратегии толкования слов обыденного метаязыкового сознания и их применение в учебной лексикографии // Филологические науки. Вопросы теории и практики. № 8, ч. 2. С. 77-81.

Ростова А. Н., 2000. Метатекст как форма экспликации метаязыкового сознания (на материале говоров Сибири). Томск : Изд-во Том. ун-та, $2000.193 \mathrm{c}$.

Ростова А. Н., 2006. Языковое мышление в концепции И.А. Бодуэна де Куртенэ и в современной лингвистике // III Международные Бодуэновские чтения: И.А. Бодуэн де Куртенэ и современные проблемы теоретического и прикладного языкознания : труды и материалы : в 2 т. / под общ. ред. К. Р. Галиуллина, Г. А. Николаева. Казань : Казанский гос. ун-т. T. 2. C. 22-26.

Ростова А. Н., 2008. Обыденное метаязыковое сознание: статус и аспекты изучения // Обыденное метаязыковое сознание и наивная лингвистика : межвуз. сб. науч. тр. / отв. ред. А. Н. Ростова. Кемерово ; Барнаул : Изд-во Алт. ун-та. C. 49-57.

Трофимова Е. Б., 2009. «Обыденное языковое сознание»: размышления на заданную тему // Обыденное метаязыковое сознание: онтологические и гносеологические аспекты / отв. ред. Н. Д. Голев. Томск : Томский гос. пед. ун-т. Ч. II. С. 46-51.

Ундармаа Д., 2014. Обыденное языковое сознание и способы его описания // Общетеоретические и типологические проблемы языкознания : сб. науч. ст. / отв. ред. У. М. Трофимова. Бийск : Алтайская гос. акад. образования им. В.М. Шукшина. С. 45-50.

Шапилова Н. И., 2010. Метаязыковые рефлексивы в художественном дискурсе (на материале произведений В.П. Астафьева) // Обыденное метаязыковое сознание: онтологические и гносеологические аспекты / отв. ред. Н. Д. Голев. Кемерово : Кемеровский гос. ун-т. Ч. III. C. $110-117$.

Шафтельская Н. В., 2012. Метаязыковое сознание как часть языкового сознания // Язык и культура : сб. ст. / отв. ред. С. К. Гураль. Томск : Томский гос. ун-т. С. 125-127.

Шумарина М. Р., 2009. Обыденное метаязыковое сознание в зеркале художественного текста // Обыденное метаязыковое сознание: онтологические и гносеологические аспекты / отв. ред. Н. Д. Голев. Томск : Томский гос. пед. ун-т. Ч. II. С. 210-222.

Шумарина М. Р., 2010. «Наивная» социолингвистика // Обыденное метаязыковое сознание: онтологические и гносеологические аспекты
/ отв. ред. Н. Д. Голев. Кемерово : Кемеровский гос. ун-т. Ч. III. С. 301-313.

Шумарина М. Р., 2011. Язык в зеркалехудожественного текста. (Метаязыковая рефлексия в произведениях русской прозы). М. : Флинта : Наука. 325 с.

\section{REFERENCES}

Bazylev V.N., 2012. Relevance and irrelevance of metalanguage knowledge as categories of diachronic description of everyday experience. Golev N.D., ed. Obydennoe metayazykovoe soznanie: ontologicheskie i gnoseologicheskie aspekty. Kemerovo, Izd-vo KGU, Part 4, pp. 231-241.

Blinova O.I., 2012. Lexicographic method of research in metalanguage consciousness. Golev N.D., ed. Obydennoe metayazykovoe soznanie: ontologicheskie i gnoseologicheskie aspekty. Kemerovo, Izd-vo KGU, Part 4, pp. 168-177.

Golev N.D., 2008. Peculiarities of modern metalinguistic consciousness reflected in discussions about language construction. Vestnik Tomskogo gosudarstvennogo universiteta. Filologiya [Tomsk State University Journal of Philology], no. 3 (4), pp. 5-17.

Golev N.D., 2009a. Obydennoe metajazykovoe soznanie kak ontologo-gnoseologicheskij fenomen (k poiskam «lingvognoseologem») [Ordinary metalanguage consciousness as an ontological and gnoseological phenomenon (to the search for 'linguistic gnoseologems')]. Golev N.D., ed. Obydennoe metayazykovoe soznanie: ontologicheskie i gnoseologicheskie aspekty. Kemerovo; Barnaul, Izd-vo Altayskogo gos. un-ta, vol. 1, pp. 7-40.

Golev N.D., 2009b. The modern Russian everyday metalanguage consciousness between science and the school course of the Russian language ('correctness' as the basic postulate of naive linguistics). Golev N.D., ed. Obydennoe metayazykovoe soznanie: ontologicheskie $i$ gnoseologicheskie aspekty. Tomsk, Tomskiy gos. ped. un-t, Part 2, pp. 261-282.

Golev N.D., 2012. Variability of the metalanguage consciousness of students-philologists and academic pluralism (antinomical analysis of the problem). Golev N.D., ed. Obydennoe metayazykovoe soznanie: ontologicheskie $i$ gnoseologicheskie aspekty. Kemerovo, Izd-vo KGU, Part 4, pp. 306-330.

Dudareva Ya.A., 2010. Associative and interpretative activity of ordinary Russian speakers in determining the identity, similarity and difference of trademarks. Golev N.D., ed. Obydennoe metayazykovoe soznanie: ontologicheskie $i$ 
gnoseologicheskie aspekty. Kemerovo, Izd-vo KGU, Part 3, pp. 286-292.

Efremov V.A., 2009. 'Man' and 'woman' in the Russian language picture of the world. Saint Petersburg, Izd-vo RGPU im. A.I. Gertsena. 184 p.

Kim L.G., 2010. Text as an object of the metalinguistic activity of the interpreter. Golev N.D., ed. Obydennoe metayazykovoe soznanie: ontologicheskie i gnoseologicheskie aspekty. Kemerovo, Izd-vo KGU, Part 3, pp. 94-109.

Kolyaseva A.F., 2014. Terminology in the light of language consciousness studies. Filologiya $i$ chelovek, no. 2, pp. 151-161.

Kravchenko M.A., Kravchenko O.V., 2015. On correlation of the concepts 'linguistic consciousness' and 'meta-linguistic consciousness'. Filologicheskie nauki. Voprosy teorii i praktiki [Philological Sciences. Issues of Theory and Practice], no. 9, part 1, pp. 105-108.

Kuzmina N.A., 2009. Autocommenting as a form of manifestation of the metalanguage consciousness (on the material of modern Russian poetry). Golev N.D., ed. Obydennoe metayazykovoe soznanie: ontologicheskie i gnoseologicheskie aspekty. Tomsk, Tomskiy gos. ped. un-t, Part 2, pp. 192-209.

Levental I.V., 2014. Interpretation strategies of words of ordinary metalinguistic consciousness and their application in academic lexicography. Filologicheskie nauki. Voprosy teorii i praktiki [Philological Sciences. Issues of Theory and Practice], no. 8, part 2, pp. 77-81.

Rostova A.N., 2000. Metatext as a form of explication of the metalanguage consciousness (on the material of the dialects of Siberia). Tomsk, Izd-vo Tom. un-ta. 193 p.

Rostova A.N., 2006. Linguistic thinking in the conception of I.A. Baudouin de Courtenay and in modern linguistics. Galiullin K.R., Nikolaev G.A., eds. III Mezhdunarodnye Boduenovskie chteniya: I.A. Boduen de Kurtene i sovremennye problemy teoreticheskogo i prikladnogo yazykoznaniya: trudy i materialy: $v 2$ t. Kazan, Kazanskiy gos. un-t, vol. 2, pp. 22-26.

Rostova A.N., 2008. Ordinary metalanguage consciousness: status and aspects of study. Rostova A.N., ed. Obydennoe metayazykovoe soznanie i naivnaya lingvistika: mezhvuz. sb. nauch. tr. Kemerovo; Barnaul, Izd-vo Alt. un-ta, pp. 49-57.

Trofimova E.B., 2009. Ordinary linguistic consciousness: reflections. Golev N.D., ed. Obydennoe metayazykovoe soznanie: ontologicheskie $i$ gnoseologicheskie aspekty. Tomsk, Tomskiy gos. ped. un-t, Part 2, pp. 46-51.

Undarmaa D., 2014. Ordinary linguistic consciousness and the ways of its description. Trofimova U.M., ed. Obshcheteoreticheskie i tipologicheskie problemy yazykoznaniya: sb. nauch. st. Bijsk, Altayskaya gos. akad. obrazovaniya im. V.M. Shukshina, pp. 45-50.

Shapilova N.I., 2010. Metalanguage reflexions in the fiction discourse (based on the works by V.P. Astafyev). Golev N.D., ed. Obydennoe metayazykovoe soznanie: ontologicheskie $i$ gnoseologicheskie aspekty. Kemerovo, Izd-vo KGU, Part 3, pp. 110-117.

Shaftelskaya N.V., 2012. Metalanguage consciousness as a part of linguistic consciousness. Gural S.K., ed. Yazyk i kultura: sb. st. Tomsk, Izd-vo Tom. un-ta, pp. 125-127.

Shumarina M.R., 2009. Ordinary metalanguage consciousness in the mirror of a fiction text. Golev N.D., ed. Obydennoe metayazykovoe soznanie: ontologicheskie i gnoseologicheskie aspekty. Tomsk, Tomskiy gos. ped. un-t, Part 2, pp. 210-222.

Shumarina M.R., 2010. 'Nanve' sociolinguistics. Golev N.D., ed. Obydennoe metayazykovoe soznanie: ontologicheskie $i$ gnoseologicheskie aspekty. Kemerovo, Izd-voKGU, Part 3, pp. 301-313.

Shumarina M.R., 2011. Language in the mirror of a fiction text (Metalanguage reflexion in the works of Russian prose). Moscow, Flinta; Nauka Publ. 325 p.

\section{Information about the Author}

Evgeniy B. Ivannikov, Postgraduate Student, Department of Russian Language, Herzen State Pedagogical University, Naberezhnaya reki Moyki , 8, 191186 Saint Petersburg, Russia, ivannikov_evgeni@mail.ru,https://orcid.org/0000-0001-5529-6230

\section{Информация об авторе}

Евгений Борисович Иванников, аспирант кафедры русского языка, Российский государственный педагогический университет им. А.И. Герцена, Набережная реки Мойки, 8, 191186 г. Санкт-Петербург, Россия, ivannikov_evgeni@mail.ru, https://orcid.org/0000-0001-5529-6230 